\title{
Lateral displacement of the mandible in Rhesus monkeys
}

\author{
JOHN R. BLANKENSHIP and SIGURD P. RAMFJORD \\ The Veterans Administration Hospital and The University of Michigan, Ann Arbor, \\ Michigan
}

\section{Summary}

Lateral displacement of the mandible was induced experimentally in five adult male Rhesus monkeys. Following from $2 \frac{1}{2}$ weeks to 19 months, the animals were sacrificed and examined histologically. Two of the monkeys received $\mathrm{H}^{3}$ proline 4 months prior to sacrifice and radioautographs were prepared. The lateral displacement apparently caused great discomfort because the monkeys refused to eat and lost weight rapidly for a few months. After about 12 months, the monkeys could again eat their normal diet to the extent they started to gain weight slowly.

The histological and radio-autographic findings indicated almost no changes of the articular surfaces of the temporomandibular joints. However, extensive reorganization of the neck of the condyles was observed. Severe periodontal trauma and extensive movements of the teeth occurred in spite of the fact that the teeth in each jaw were splinted firmly together.

\section{Introduction}

The report of Carlsson et al. (1967) on pain and morphological changes in the temporomandibular joint associated with lateral displacement of the mandible, gave the inspiration for the present study. Association is not sufficient to establish cause and effect relationship; experimental confirmation or rejection is needed. The hypothesis that pain and certain morphological changes in the temporomandibular joint may be caused by lateral displacement in closure from centric relation to centric occlusion therefore should be tested under controlled experimental conditions. Since experiments with a potential harmful effect cannot be performed in humans, the next best alternative is to use an experimental animal with a similar masticatory system. The experimental animals of choice are monkeys although it is understood that findings of this type never can be transferred conclusively to humans.

The experimental techniques of past studies (Hiniker \& Ramfjord, 1966; Ramfjord \& Hiniker, 1966; Ramfjord \& Enlow, 1971) on anterior and posterior displacement of the mandible seemed applicable also to an investigation of the morphological effects of lateral displacement related to time. 


\section{Materials}

Five adult female Rhesus monkeys were selected for the study. The third molars were fully or partially errupted and the monkeys weighed from 12 to $14 \mathrm{lb}$ at the start of the study. They all had gingivitis or incipient periodontitis with calculus and some shallow periodontal pockets extending 1-2 $\mathrm{mm}$ apically to the cementum-enamel junction.

The monkeys were fed Purina Monkey Chow supplemented with some fresh fruits and vegetables. They were allowed at least 1 month of adaptation to the environment of their quarters before the experimental procedures were initiated. Temperature and humidity in the quarters were controlled rigidly.

\section{Methods}

Photographs, dental radiographs, and casts of the teeth were secured. The monkeys were given a prophylaxis, and the maxillary right cuspids were extracted to allow for lateral displacement of the mandible to the right side. Gingivectomy was done when needed to expose the crowns of the teeth sufficiently for retention of the appliances.

Two, one piece cast gold splints were fabricated to fit around all maxillary and all mandibular teeth. Added gold on the palatal aspect of the left maxillary cuspid guided the mandible 3-4 mm towards the right side of the maxillary midline in full occlusion closure (Figs 1a-c). The splints did not cover any of the occlusal surfaces, and with the monkeys anaesthetized the jaws could be brought together to occlusal contacts except for the incisors where the bite was slightly open. The splints were cemented in place. Previous experience had indicated that such splints have a tendency to become

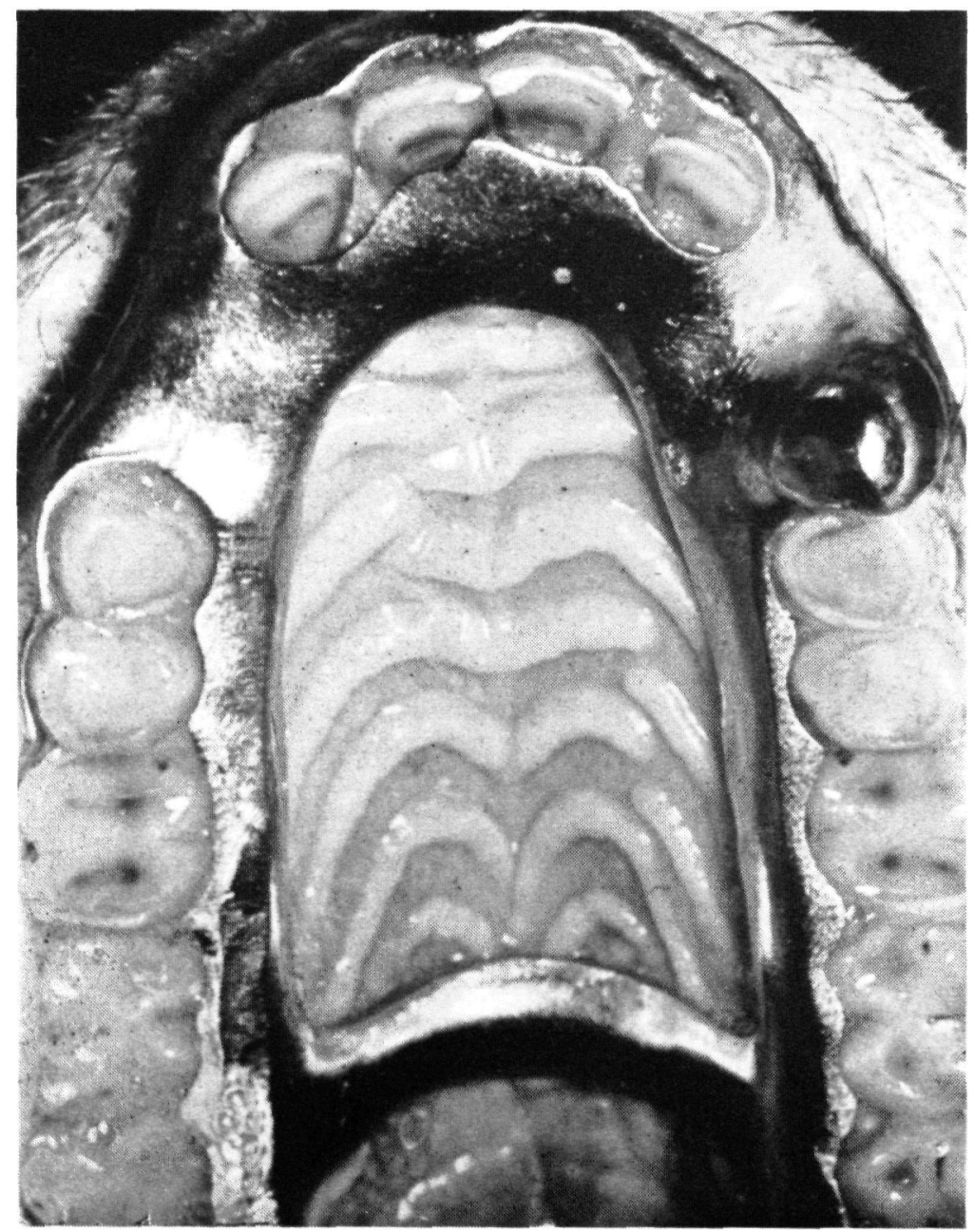

Fig. 1a. Occlusal view of maxillary splint. 


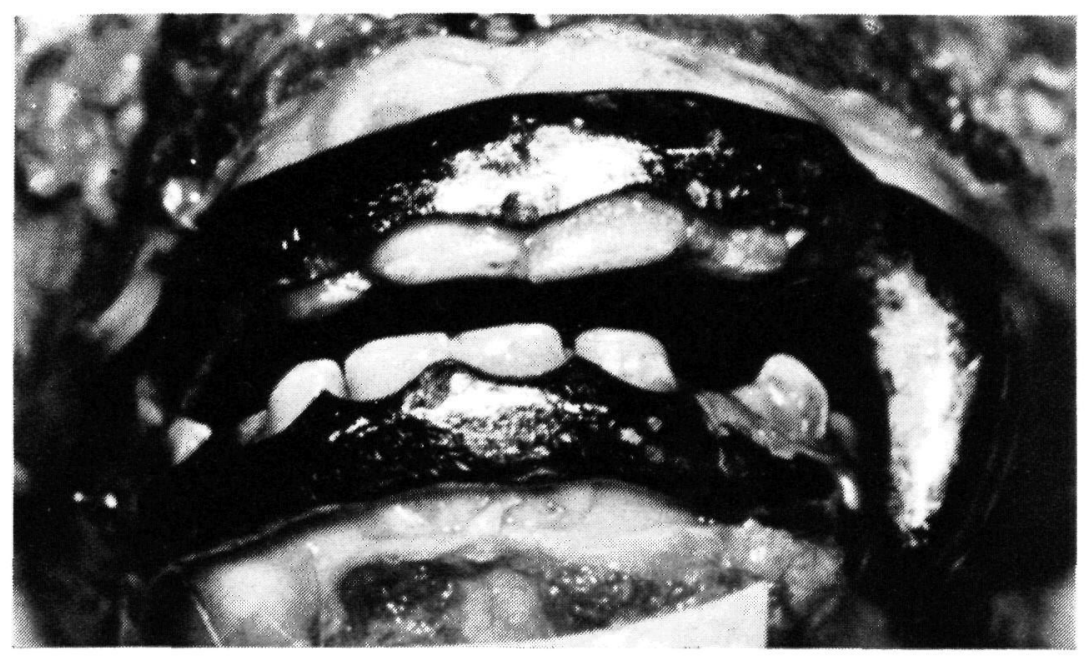

Fig. 1b. Splints in place when the monkey was sacrificed $2 \frac{1}{2}$ weeks after insertion. Note open bite in the anterior region.

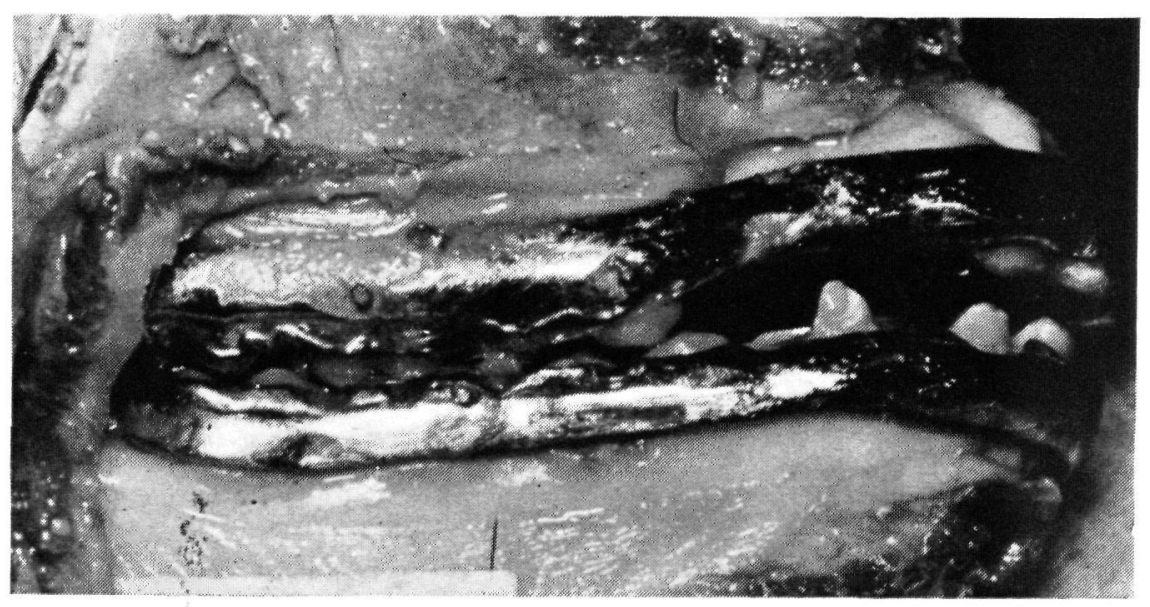

Fig. 1c. Same monkey as Fig. 1b at sacrifice. Left side. Bite closed in the posterior region.

loose, so a number of threaded screw pins were placed through the buccal part of the splints into the teeth to assure an unaltered position of the splint in relation to the teeth.

The monkeys were weighed and had their occlusion inspected several times during the experimental period.

One monkey was sacrificed after $2 \frac{1}{2}$ weeks. Another monkey died after $4 \frac{1}{2}$ months from refusal to eat. The remaining three monkeys were sacrificed after $6,16 \frac{1}{2}$ and 19

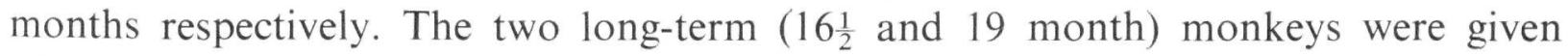
tritiated proline $(2 \mu \mathrm{Ci} / \mathrm{g}$ body weight, specific activity $5 \mathrm{Ci} / \mathrm{mM}) 4$ months before they were sacrificed, and tritiated thymidine $(1 \mu \mathrm{Ci} / \mathrm{g}$ body weight, specific activity $6.7 \mathrm{Ci} / \mathrm{mM}) 1 \mathrm{~h}$ prior to sacrifice.

A complete necropsy was performed for each monkey, and specimens from internal organs were examined histologically. No gross or microscopic evidence of systemic disease was found except for a few lung flukes (Pneumonyssus semicola) which often are found in Rhesus monkeys and do not seem to affect their systemic health significantly.

Following formalin fixation, the heads of the monkeys were bisected with a band saw and radiographs were obtained of the jaws and temporomandibular joints. About $3 \mathrm{~mm}$ thick blocks were cut of the middle parts of the temporomandibular joints in 
the frontal plane, while the anterior and posterior parts of the joints were sectioned in the sagittal plane. These blocks were embedded in celloidin and sectioned serially for the three short term ( $2 \frac{1}{2}$ weeks, $4 \frac{1}{2}$ months, and 6 months) monkeys.

For the two longer term monkeys, similar block sections from the temporomandibular joints were divided in halves. One half was embedded in celloidin and the other half in paraffin (following EDTA decalcification).

Specimens from all five monkeys were sectioned for histological study. Radioautographs of the temporomandibular joints and the periodontal structures were prepared for the two long term monkeys. Every two to three of ten sections were examined in a step serial manner.

Similar sections from temporomandibular joints and teeth embedded in celloidin were available in our laboratory from a number of monkeys that had not been used for any experiments involving occlusion. These specimens were used as controls in evaluation of the experimental findings.

\section{Direct observations}

The monkeys refused to eat their regular diet after insertion of the splints. The monkey that was sacrificed after $2 \frac{1}{2}$ weeks had lost $2 \mathrm{lb}$ of weight although it was offered supplemental food of egg and milk. The monkey that died after $4 \frac{1}{2}$ months had lost $4 \frac{1}{2} \mathrm{lb}$ (from initial 14, to $9 \frac{1}{2} \mathrm{lb}$ ), appeared very thin and had an empty stomach at the time of death. The other monkeys also lost weight initially $(2-3 \mathrm{lb})$, but were kept alive on liquid diet supplemented with egg and milk. After 6-8 months, they started to regain the lost weight, and the two long term monkeys weighed $1-2 \mathrm{lb}$ more at the time of sacrifice than at the time of insertion of the appliance. After 6-8 months the monkeys started to eat their regular monkey chow and they seemed to eat normally after 12 months, although they did not gain weight as fast as monkeys in previous studies with other types of appliances (Hiniker \& Ramfjord 1966; Ramford \& Hiniker, 1966; Ramfjord \& Enlow, 1971).

A gradually increasing opening of the bite in the incisor region was observed over the first 2-3 months, then it started to close up so at the time of sacrifice of the long term monkeys the bite was closed to provide occlusal contact for all of the teeth.

\section{Radiographic examination}

The radiographs of the temporomandibular joints did not provide clear definition of the joint surfaces. However, when the temporomandibular joints could be distinguished fairly well, they appeared to have a normal bony outline (Fig. 2).

\section{Histological and radio-autographic findings}

The histological and radio-autographic findings are described for each of the temporomandibular joints of the experimental monkeys.

Number $l$ ( $2 \frac{1}{2}$ week experimental interval). The right temporomandibular joint showed mild fibrinoid degeneration of the condylar cartilage at the lateral one-third of the articular surface. Active bone resorption was noted on the anterior medial surface of the neck of the condyle at the site of insertion of the lateral pterygoid muscle. There also was a small area of bone resorption on the anterior surface of the post-glenoid spine. The synovial cells were prominent on the surface of the disc corresponding to the area of degenerative changes on the condyle surface. A few perivascular inflammatory cells were observed in the vicinity of these degenerative changes. The condyle appeared to be positioned slightly more laterally than observed in control specimens, 


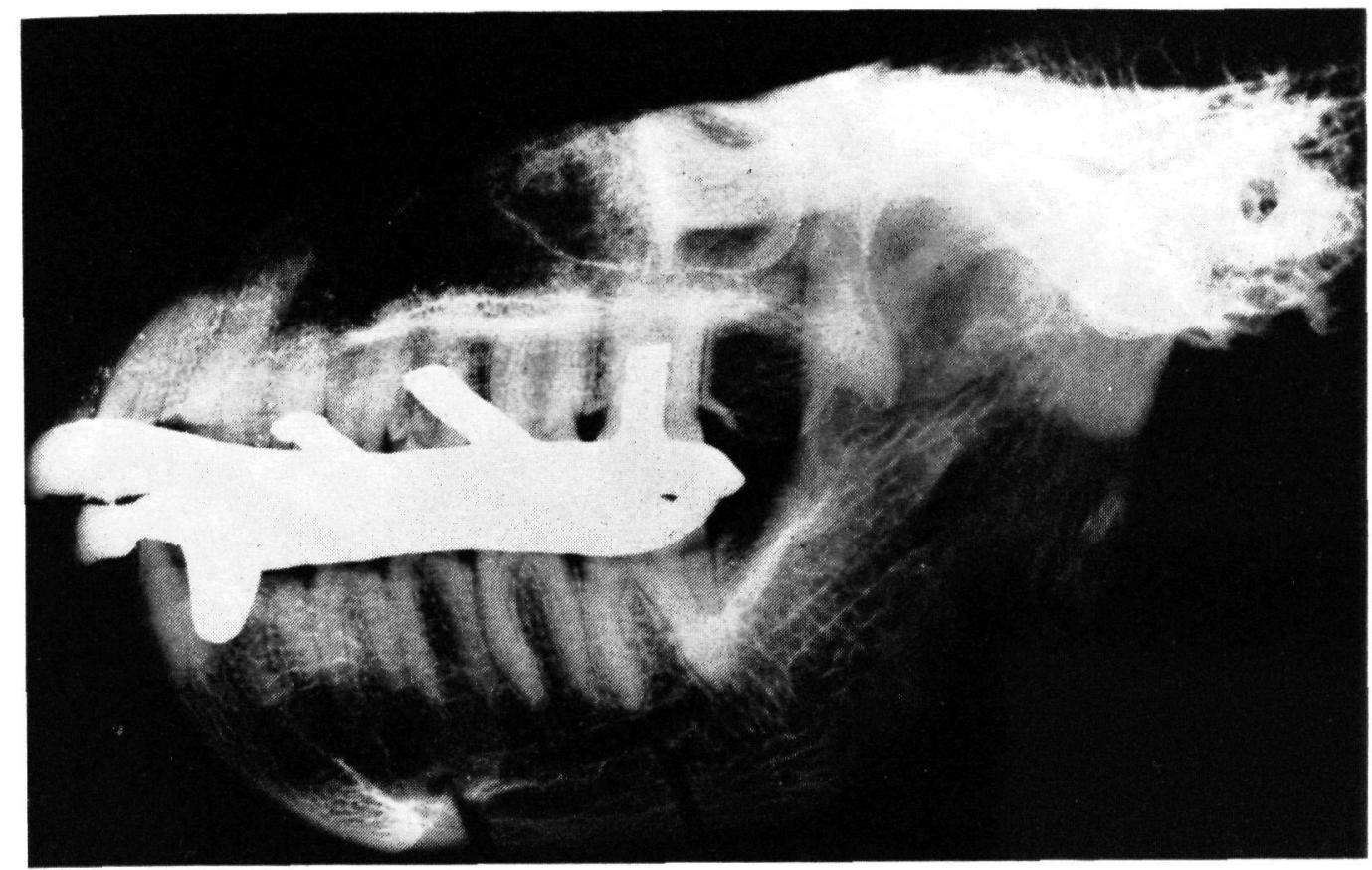

Fig. 2. Radiograph of jaws from 19 month specimen sectioned through the midsagittal plane. The temporomandibular joint appears to be normal. At this time the bite had closed to occlusal contact of all teeth.

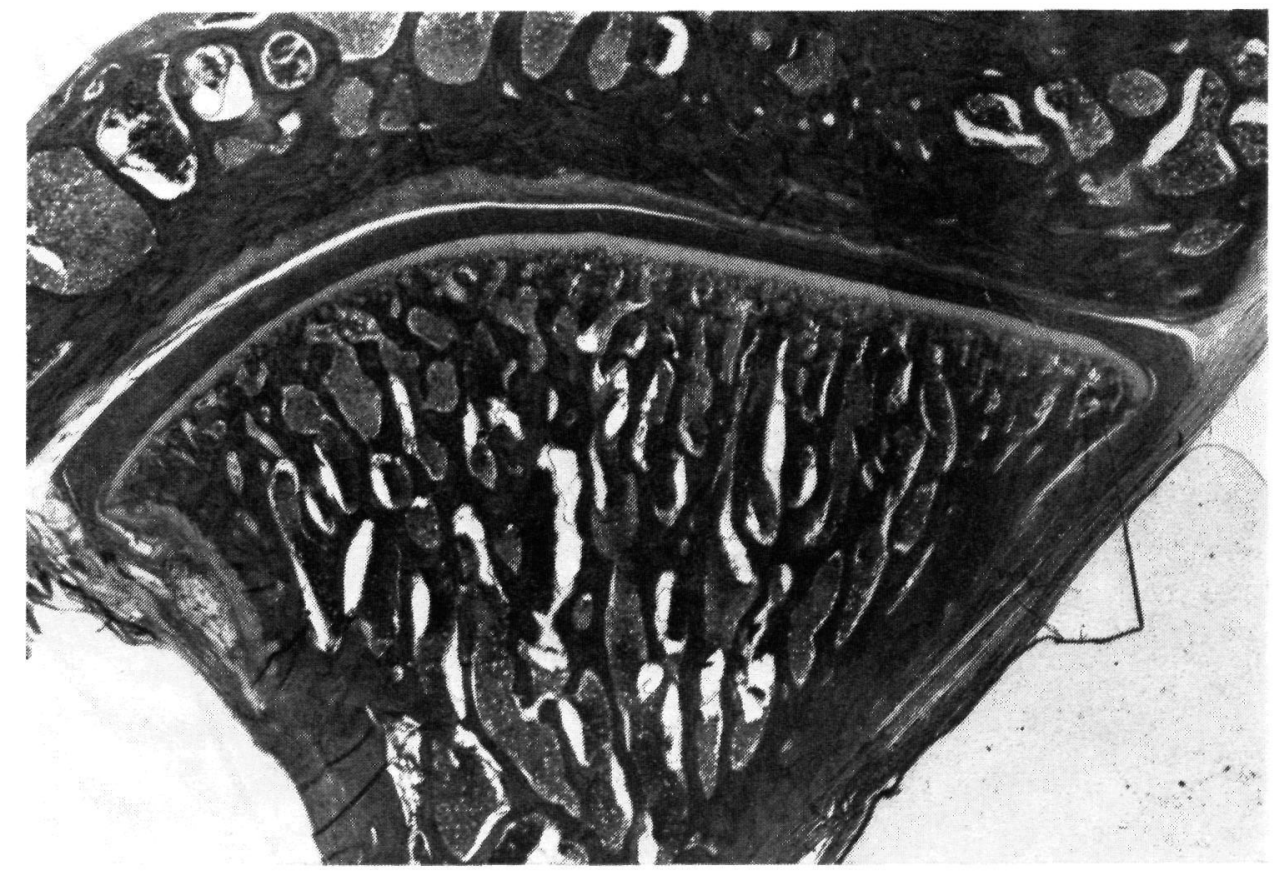

Fig. 3a. Left TMJ. $2 \frac{1}{2}$ week specimen. Normal joint relations. (Original magnification $\times 5 \cdot 5$.)

although unavoidable variations in orientation of the plane of sectioning makes such interpretations of dubious significance.

Sections in the frontal plane through the left temporomandibular joint showed normal joint relations (Figs 3a, b). However, sections in the frontal plane through temporomandibular joints in monkeys have to be interpreted with great care and with serial sections being available since the lateral pterygoid muscle is attached to the medial anterior aspect of the neck of the condyle in a deep fovea (fovea pterygoidea) in the bone (Figs 4a, b). Frontal sections through this fovea will show what may appear to be undermining bone resorption inferior to the joint surface (Figs 5a, b). However, 


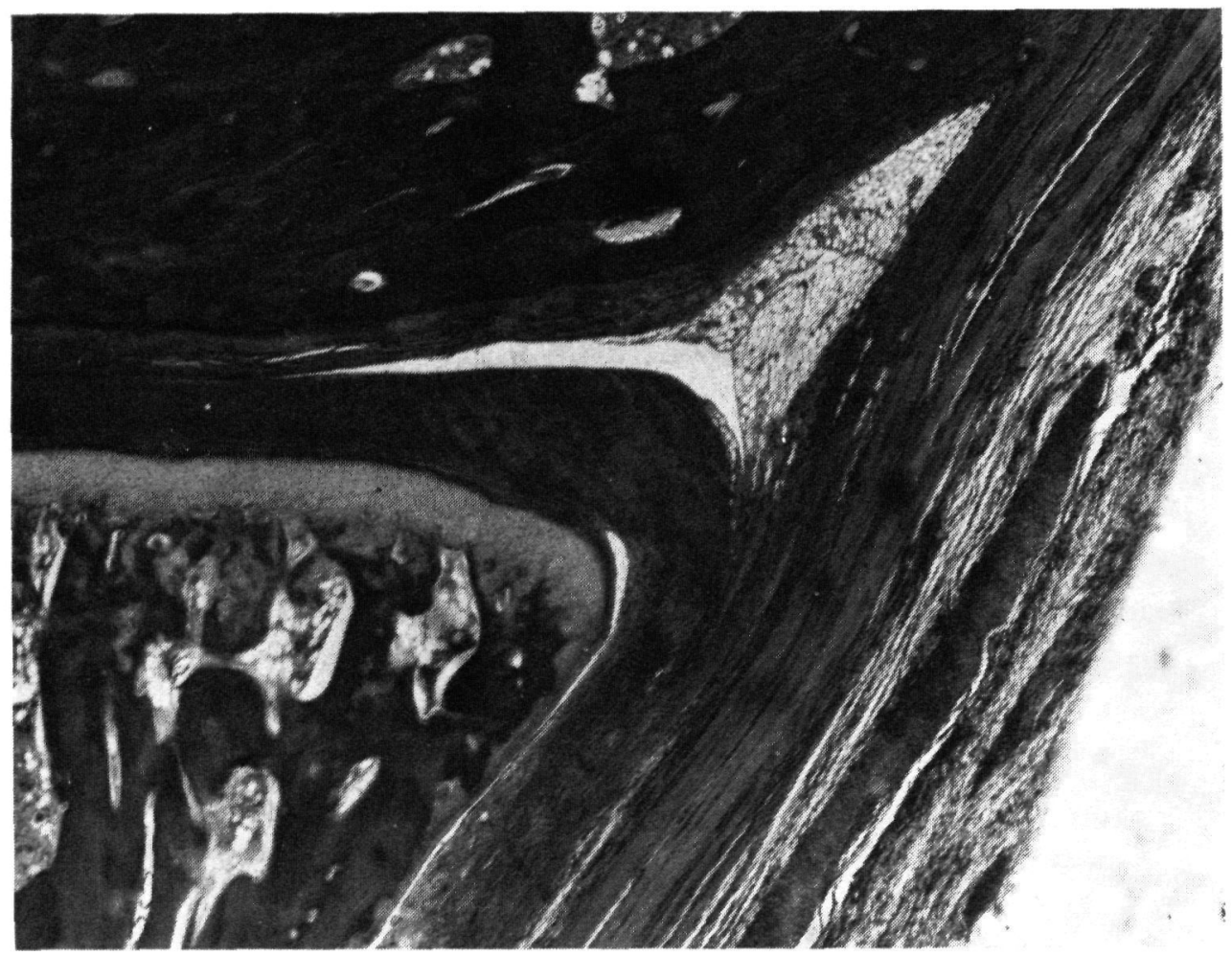

Fig. 3b. Higher magnification of the lateral aspect of the same joint as in Fig. 3a. Normal joint structures. (Original magnification $\times 21$.)

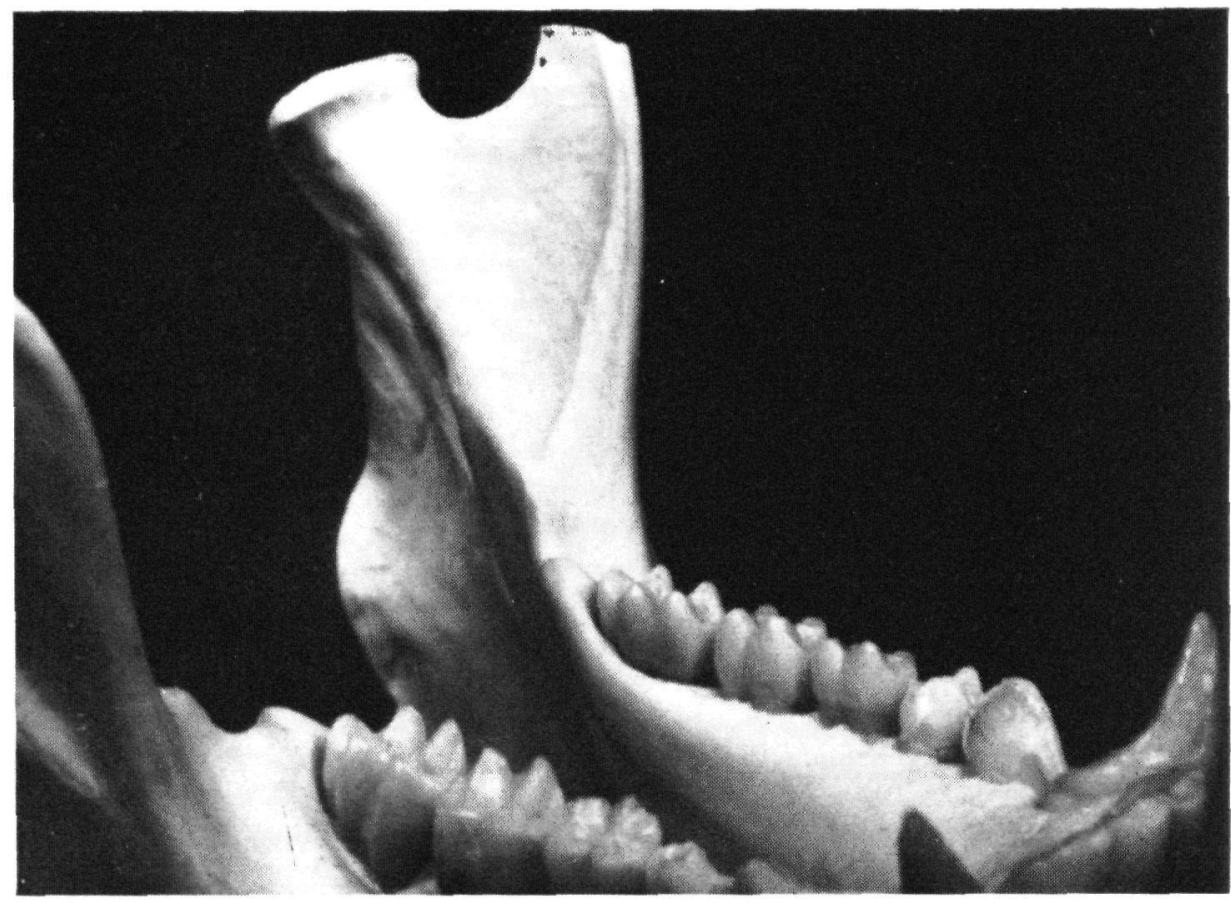

Fig. 4a. Mandible of adult Rhesus monkey. Anterior view of left condyle.

this represents a tangential cut through the sharp anterior edge of the condyle shown in Fig. 4b and does not represent a pathologically altered joint.

Number 2 (4 $\frac{1}{2}$ months experimental interval). Frontal sections through the right temporomandibular joint and the neck of the condyle indicated rapid new bone deposition on the lateral aspect of the neck of the condyle (Figs 6a, b) and new bone formation on the lateral and anterior aspects of the neck of the condyle (Fig. 6c) signifying rapid reorganization of the bony morphology in response to change in functional demand. Numerous osteoblasts and reversal lines in the bone also indicated 


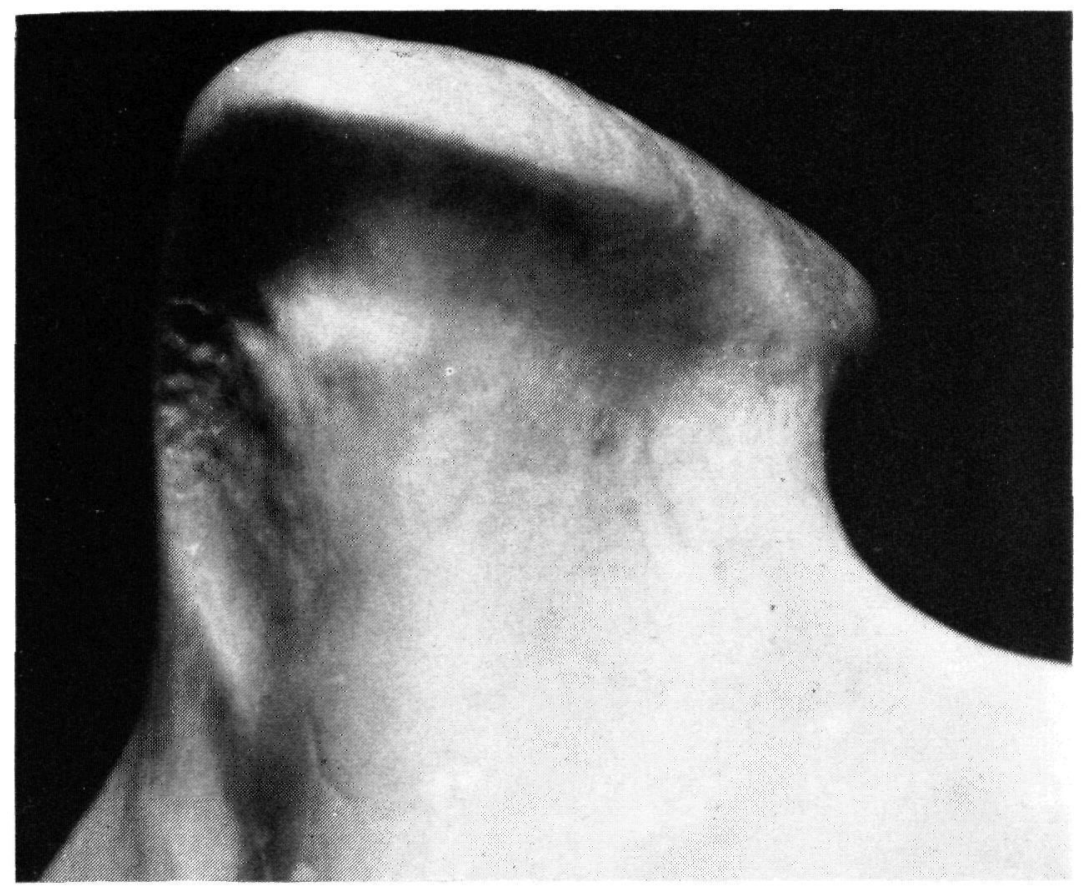

Fig. 4b. Close-up view of left condyle. Note medial fovea for insertion of lateral pterygoid muscle (fovea pterygoidea). The bony surface normally is rough in this area.

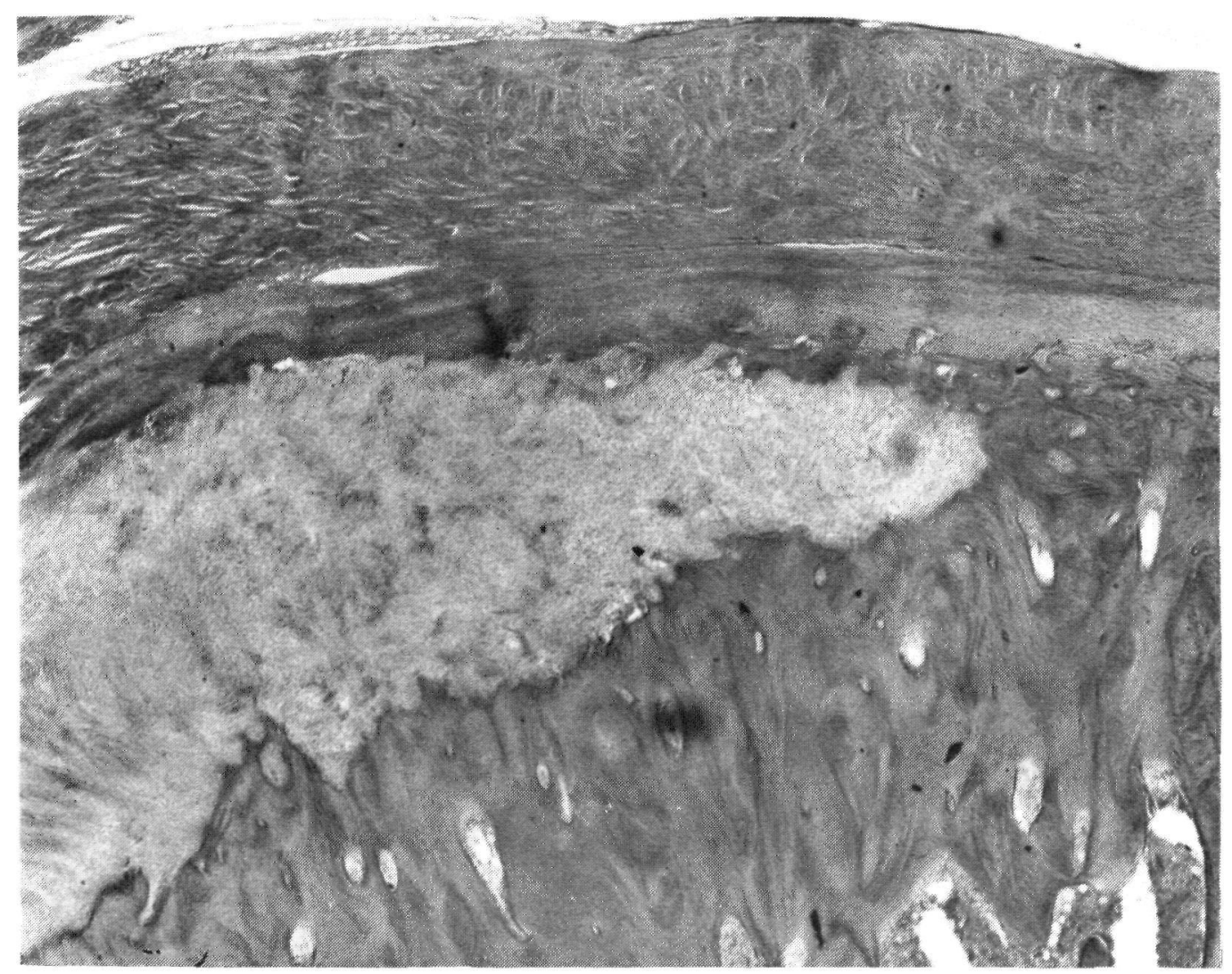

Fig. 5a. Trangential section through anterior border of left condyle. The joint is normal, and what appears to be an area of bone resorption from the left to the middle of the picture is a normal area of insertion of the lateral pterygoid muscle. (Original magnification $\times 21$.)

rapid rebuilding of the entire trabecular system of the neck of the condyle.

The coronoid process was positioned farther laterally than normal (Fig. 6d).

The articular surfaces were smooth and normal. Slight resorption and repair of bone had occurred at the medial border of the glenoid fossa (Fig. 6e).

The anterior aspect of the left condyle was positioned slightly farther medially than 


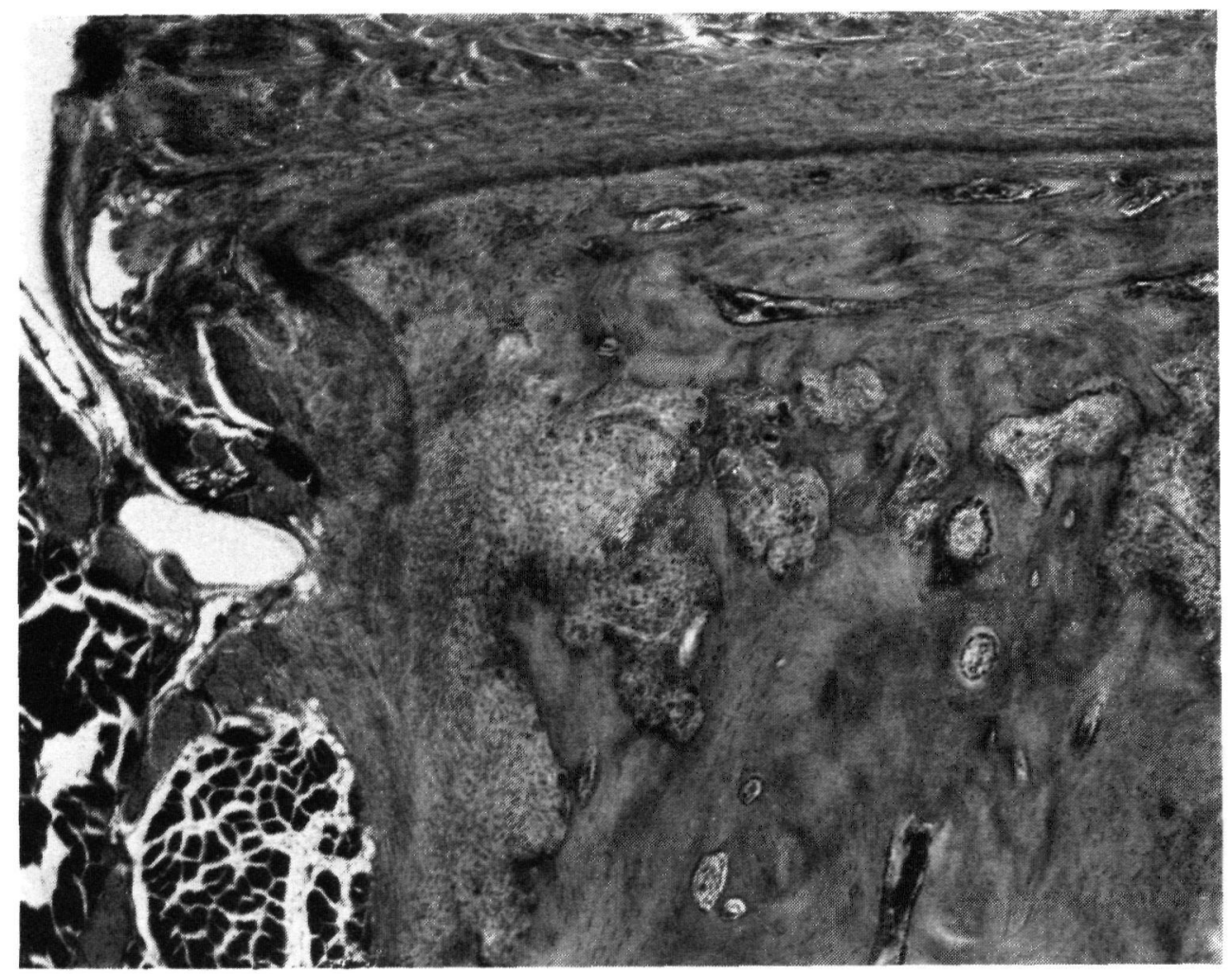

Fig. 5b. Farther posterior section from same joint as Fig. 5a. Now approaching the bottom of the fovea pterygoidea. Normal joint. (Original magnification $\times 28$ ).

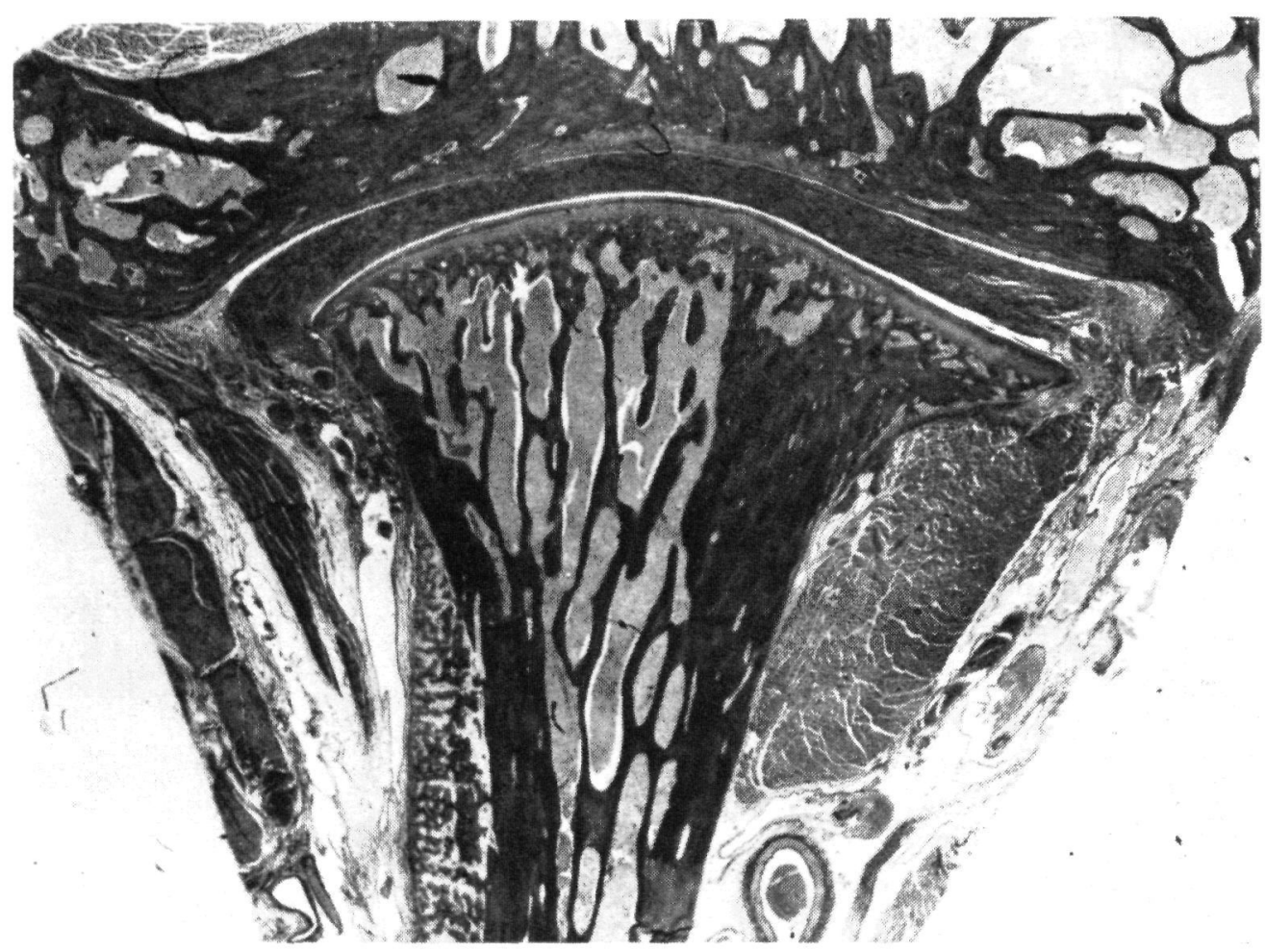

Fig. 6a. $4 \frac{1}{2}$ months specimen. Frontal sections through the right TMJ. Note heavy deposition of new bone on the lateral aspect of the neck of the condyle (to the left of the picture). (Original magnification $\times 6$.

normal. There was indication of rapid cartilage and bone formation on the distal surface of the condyle, but no unusual rebuilding was noticed on the corresponding surface of the glenoid fossa. The cartilage covering the lateral surface of the articular tuberculum appeared to be compressed, but the articulating joint surfaces were smooth and normal. 


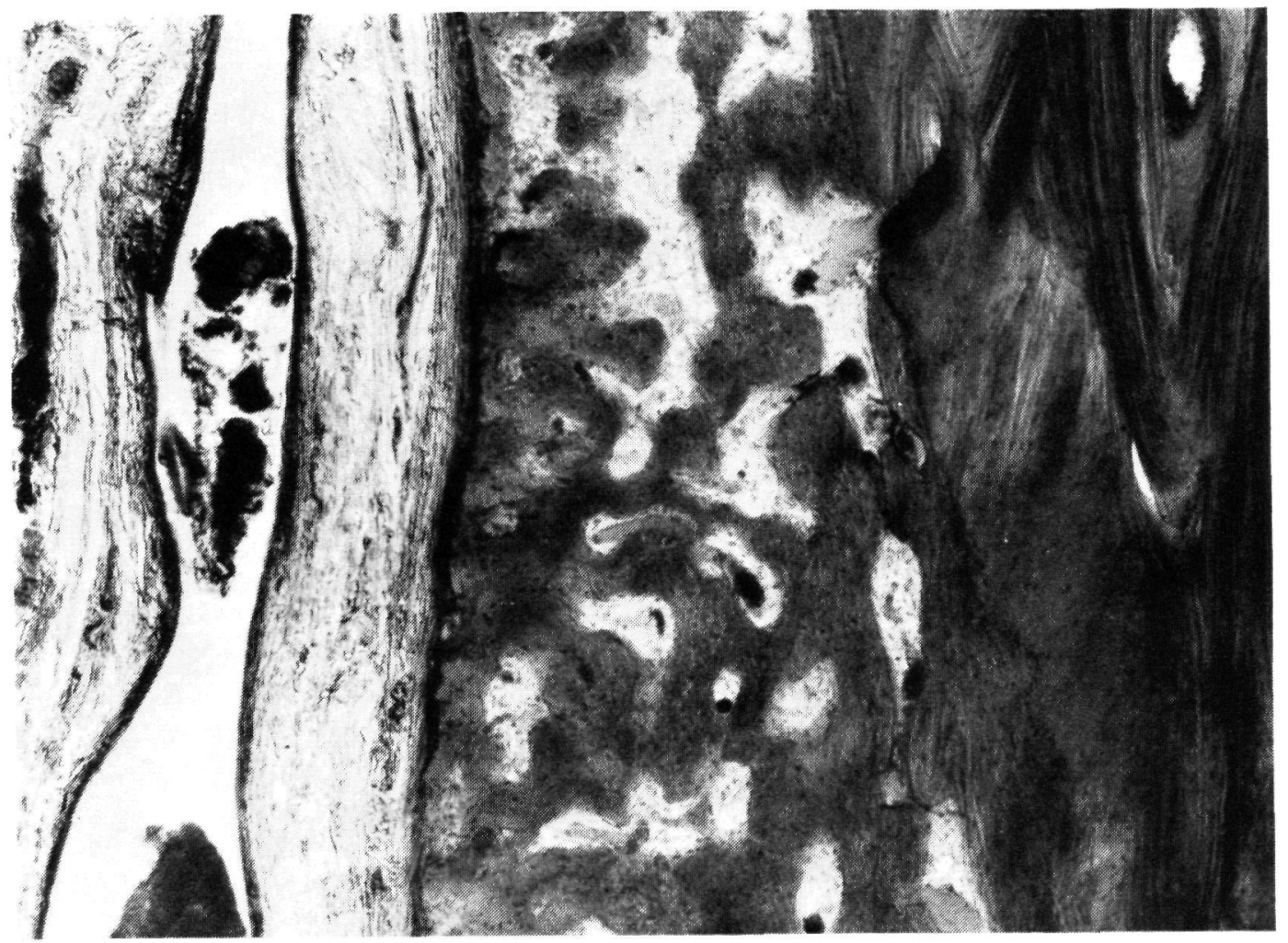

Fig. 6b. Higher magnification of new bone described in Fig. 6a (middle of picture). (Original magnification $\times 59$.)

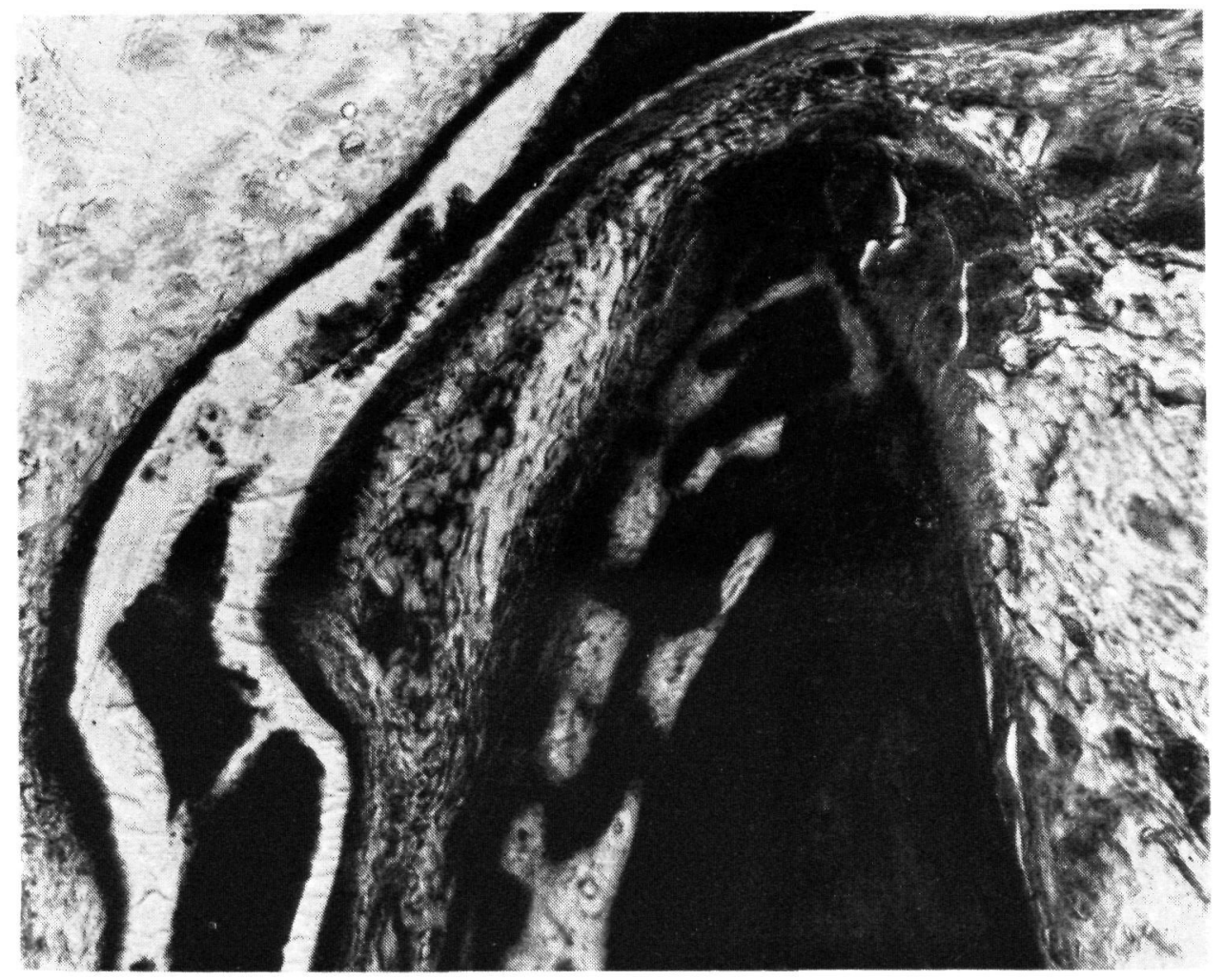

Fig. 6c. Frontal section through the anterior edge of the neck of the condyle. Same specimen as Figs $6 \mathrm{a}$ and $6 \mathrm{~b}$. Note deposition of new bone on the lateral and anterior aspects. (Original magnification $\times 70$.)

Number 3 (6 months experimental interval). All findings were similar to monkey 2 (4 $\frac{1}{2}$ months interval). The right condyle appeared to be in a slightly more lateral position than normal, and there was evidence of remodelling of bone at the neck of the condyle, although less active than in monkey 2 . The left condyle was in a slightly 


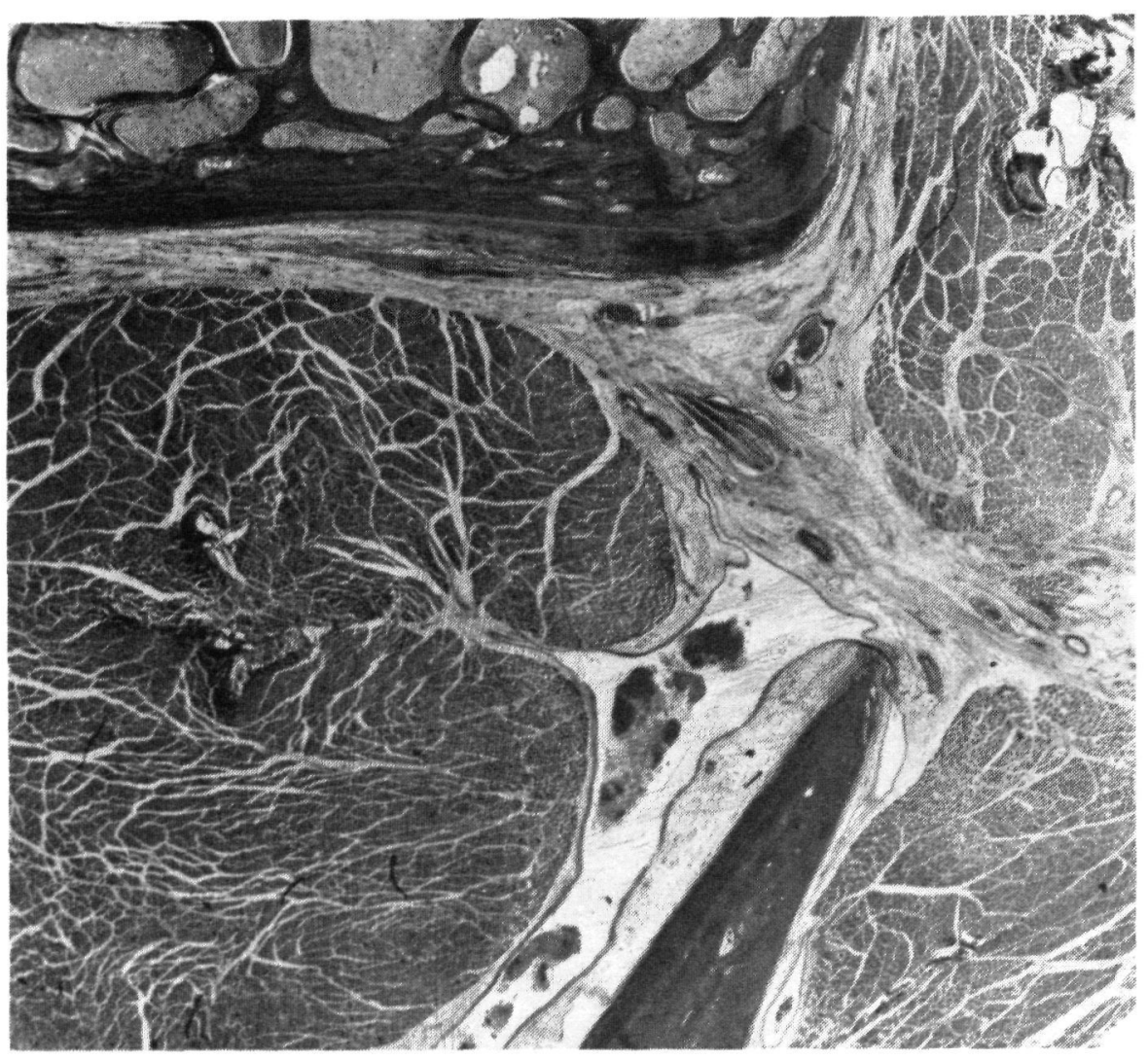

Fig. 6d. Coronoid process in lateral position. Same specimen as Figs 6a-c. (Original magnification $\times 8$.)

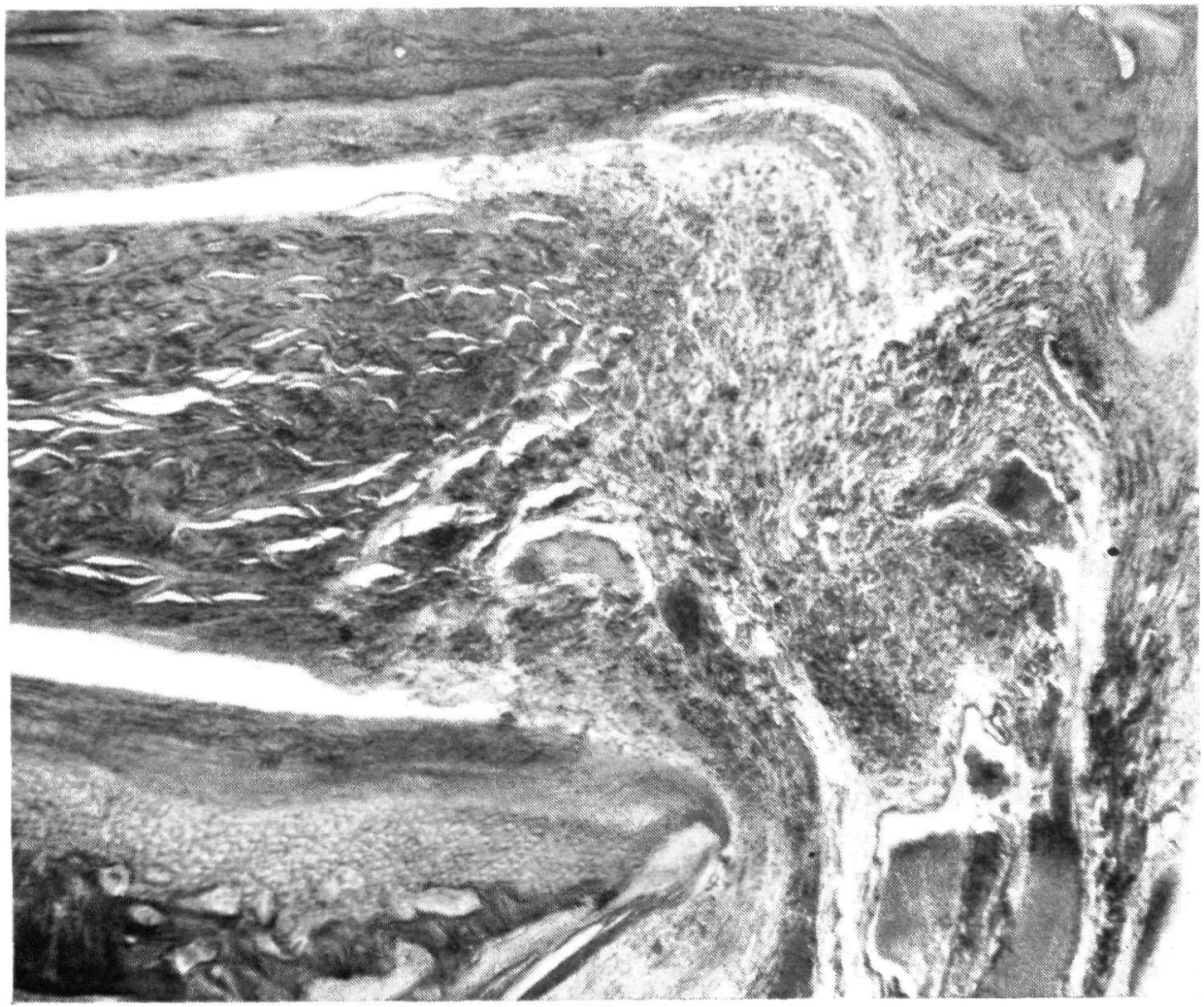

Fig. 6e. Medial aspect of the right condyle. From the same specimen as Figs 6a-d. Compression of soft tissues between the medial border of the condyle and the medial wall of the glenoid fossa. Also indication of slight bone resorption on the medial wall of the glenoid fossa. (Original magnification $\times 42$.) 


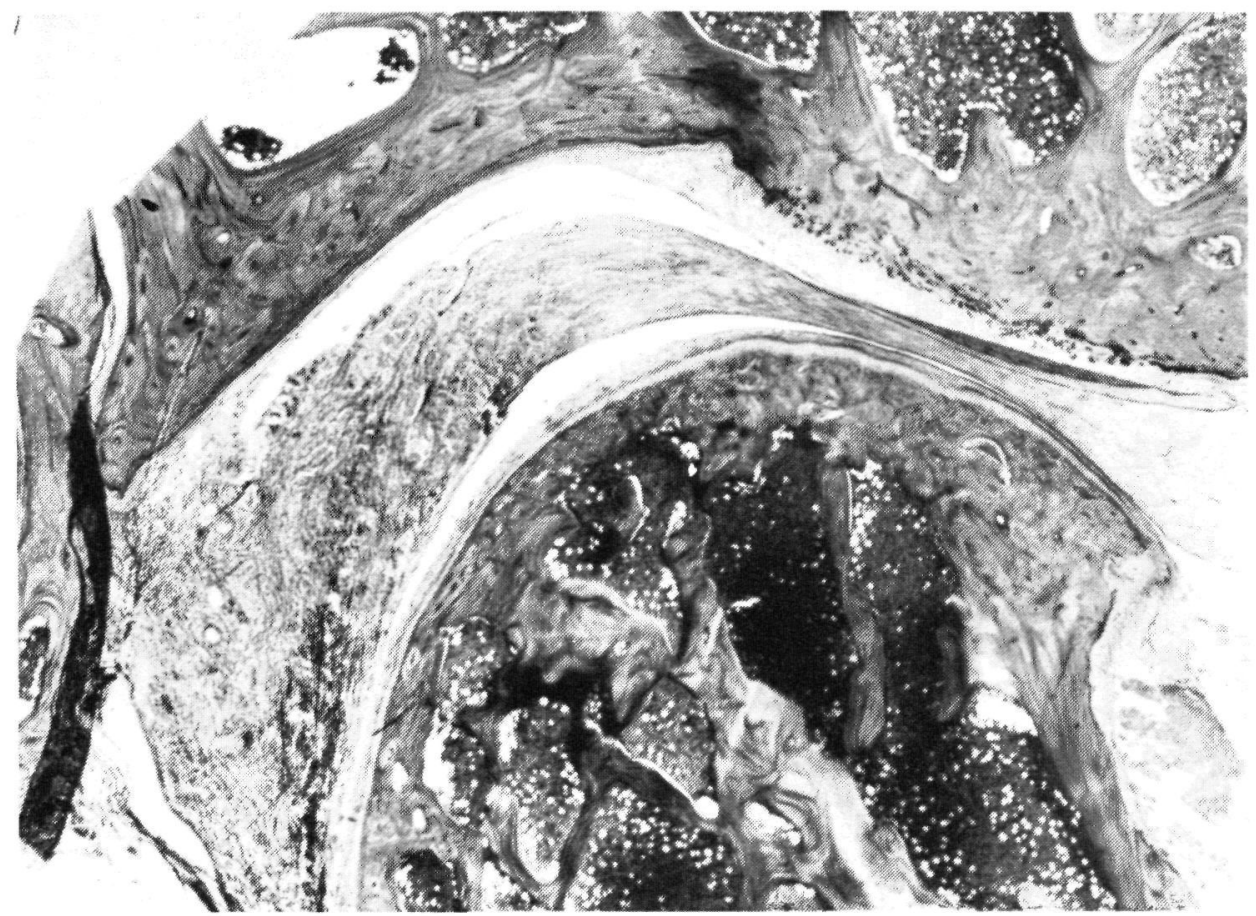

Fig. 7a. From $16 \frac{1}{2}$ months specimen. Sagittal section through the right TMJ. Normal joint surfaces. (Original magnification $\times 10$.)

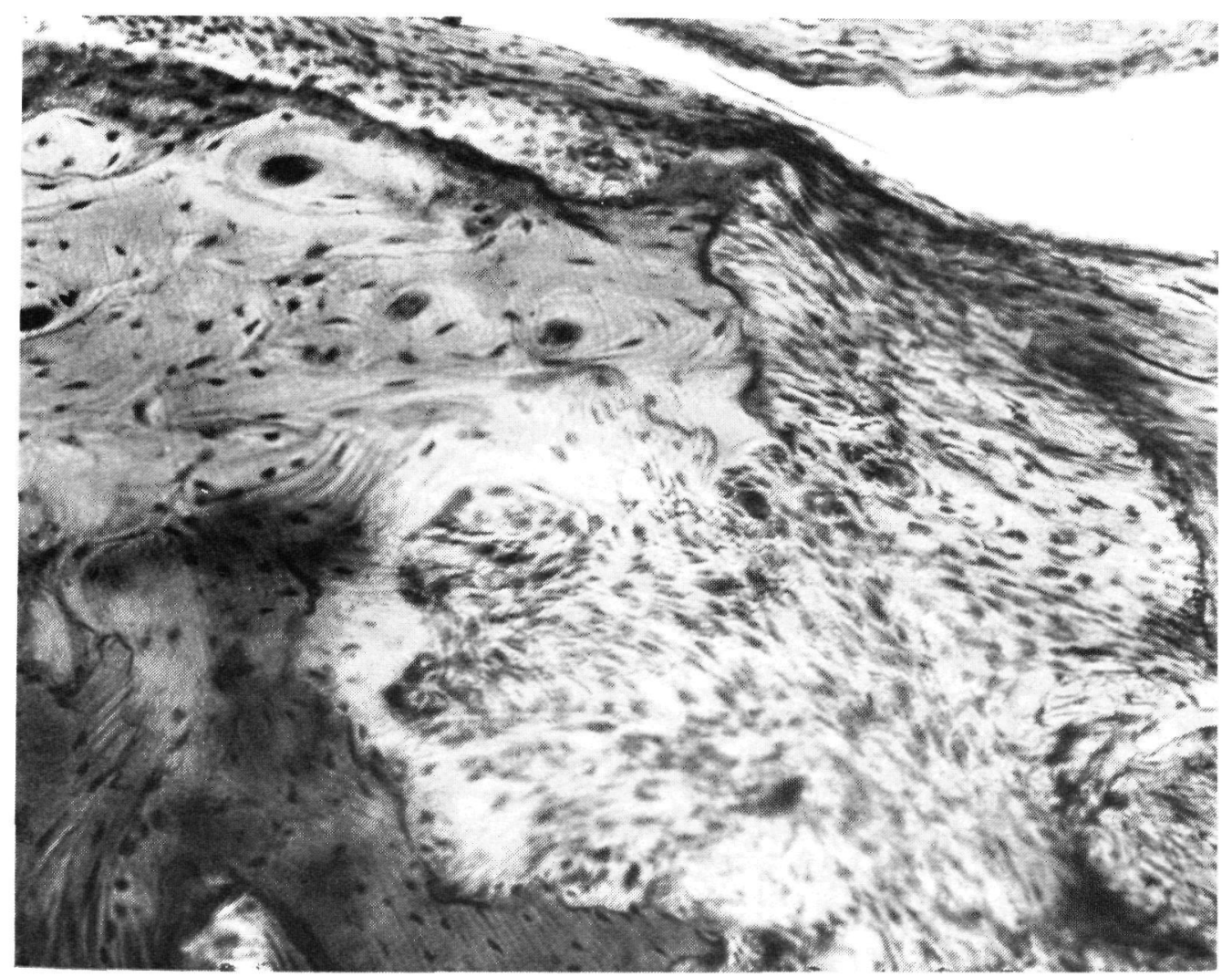

Fig. 7b. Higher magnification from Fig. 7a. Resorption and repair on the anterior aspect of the condyle. (Original magnification $\times 200$.)

medial position. A thick zone of cartilage and evidence of rapid bone formation was seen on the distal articular aspect of the condyle. Superficial resorption was found on the distal aspect of the neck of the condyle in the extreme posterior lateral sections.

Number 4 (16 $\frac{1}{2}$ months experimental interval). The articular surfaces of the right temporomandibular joint were normal (Fig. 7a). There was some evidence of resorp- 


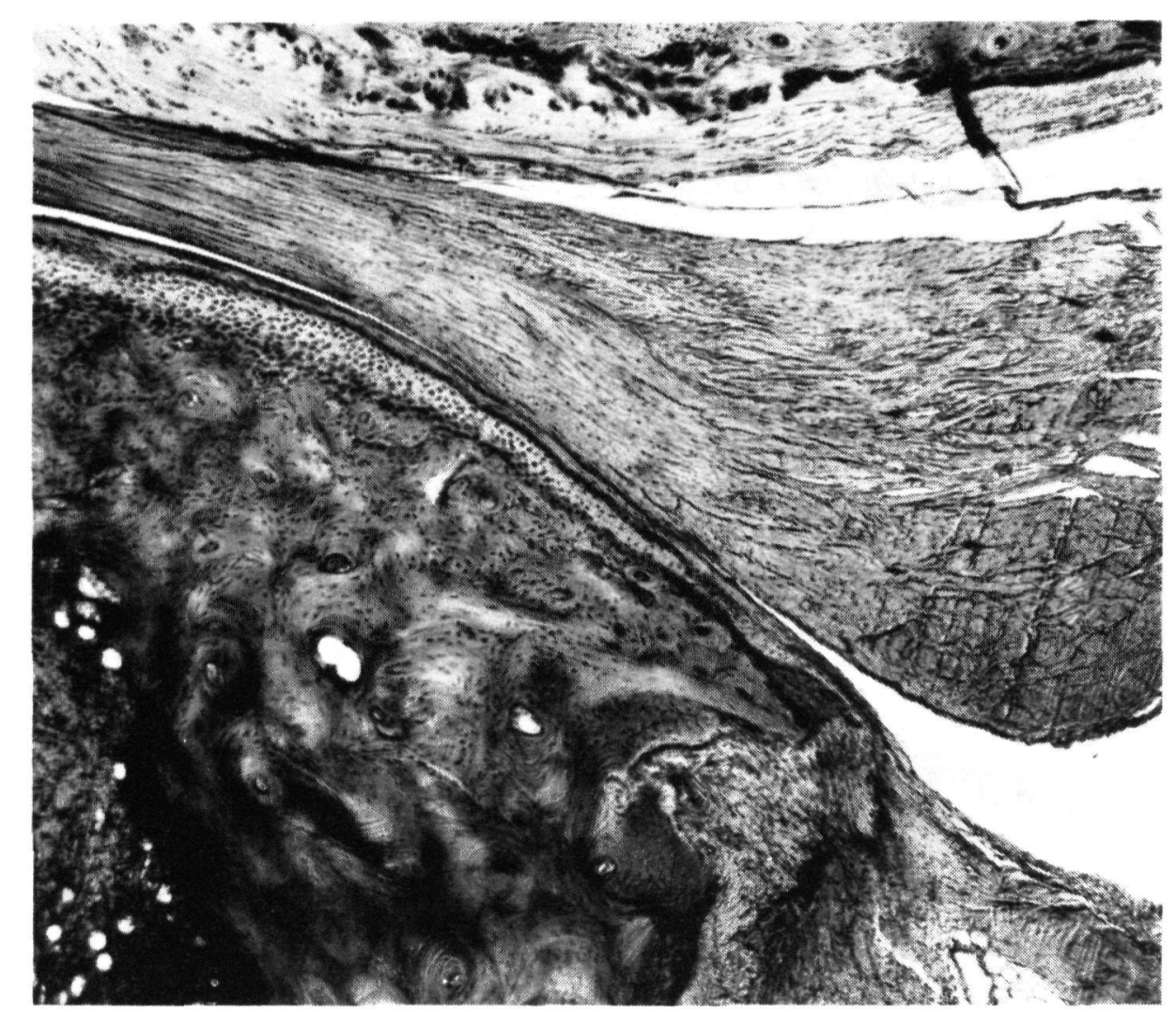

Fig. 7c. From the same specimen as Fig. 7a. Irregular pattern and some dystrophic calcification of joint cartilage on the articular tuberculum. (Original magnification $\times 55$.)

tion and repair on the anterior aspect of the condyle (Fig. 7b). The trabeculation was very heavy on the lateral surface of the neck of the condyle. The articular surfaces were smooth, but the cartilage had irregular orientation of the cells and showed some dystrophic calcification (Fig. 7c) as often seen in old monkeys. The bony surface was slightly jagged, especially on the articular tuberculum. The posterior aspect of the glenoid fossa was normal. The joint appeared flat, but similar morphology has been observed in old monkeys without anything having been done to their occlusion. The joint contours as viewed in sections are much dependent on the orientation of the blocks for sectioning and this cannot be standardized well. Even if a step serial sectioning with numbered sections is used, it becomes impossible to assess if the sections to be compared are from comparable orientations and locations in different joints.

The radio-autographs with $\mathrm{H}^{3}$ proline labelling indicated that a thin layer of new bone had formed after the labelling on the lateral surface of the neck of the condyle. Normal remodelling of the haversian canal system was observed, with no indication of specific functional reorganization patterns (Fig. 8a). There was a thin layer $(0 \cdot 1-0 \cdot 2$ $\mathrm{mm}$ ) of new bone on the anterior wall of the postglenoid spine. The bone contour over the articular surface of the condyle (Fig. 8b) and the glenoid fossa had been static over the 4 months following administration $\mathrm{H}^{3}$ proline. The medial-anterior aspect of the condyle showed reorientation of bony trabeculi.

The left temporomandibular joint was normal. The proline labelling indicated slight addition of bone on the lateral aspect of the condyle. There was indication of remodelling of haversian canals, but no definite directional pattern of the rebuilding (Fig. 9).

The articular surfaces of the condyle and the temporal bone were flat with a small spur or 'lipping' on the anterior aspect of the condyle. The cartilage covering of the bony surfaces was slightly irregular in pattern, similar to the right side and similar 


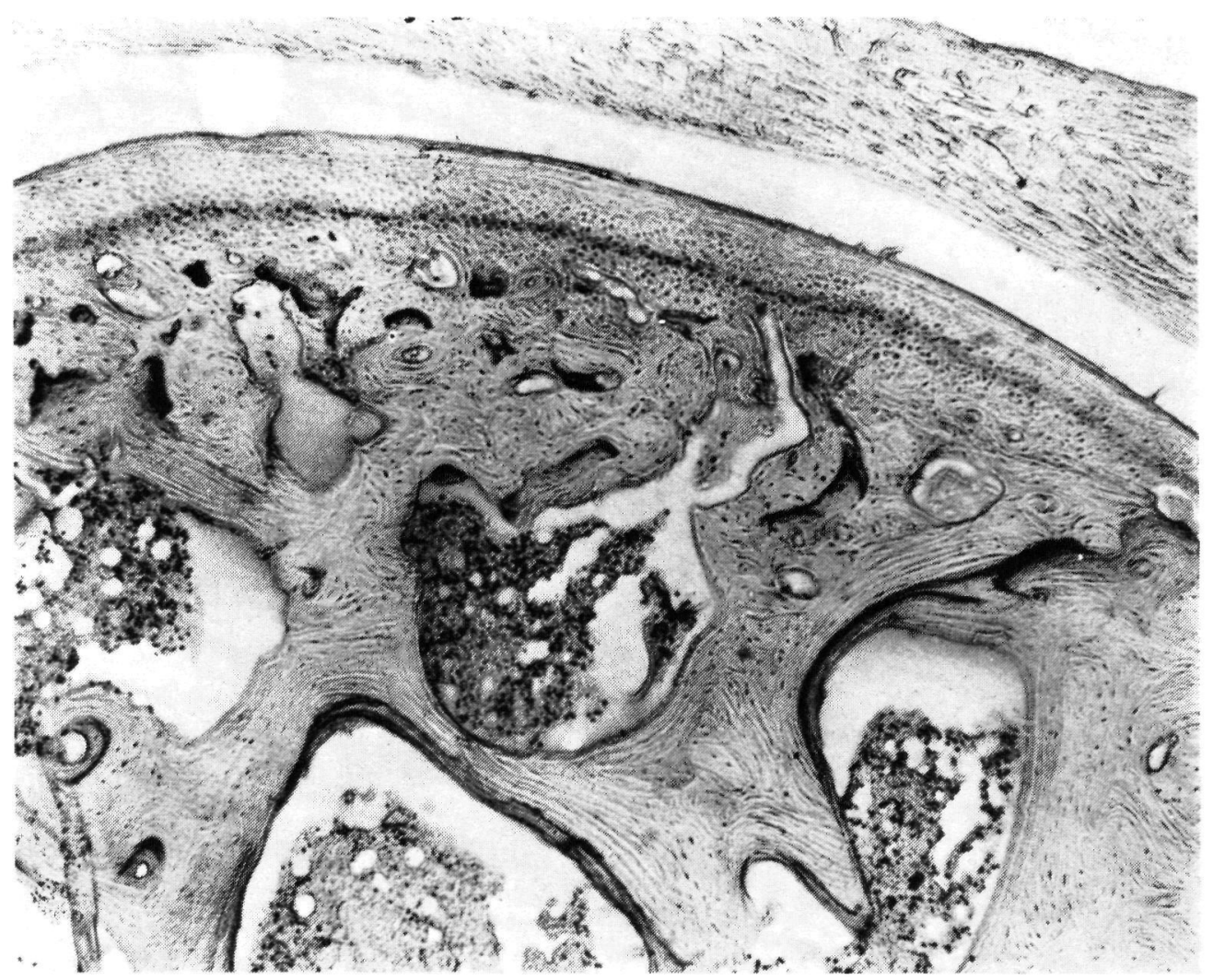

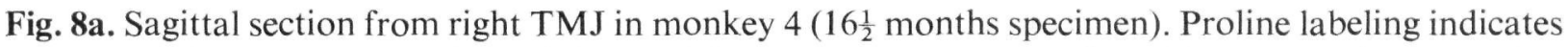
no change of the articular surface of the condylar bone. Some remodelling of bone has taken place, but without any specific growth pattern. (Original magnification $\times 55$.)

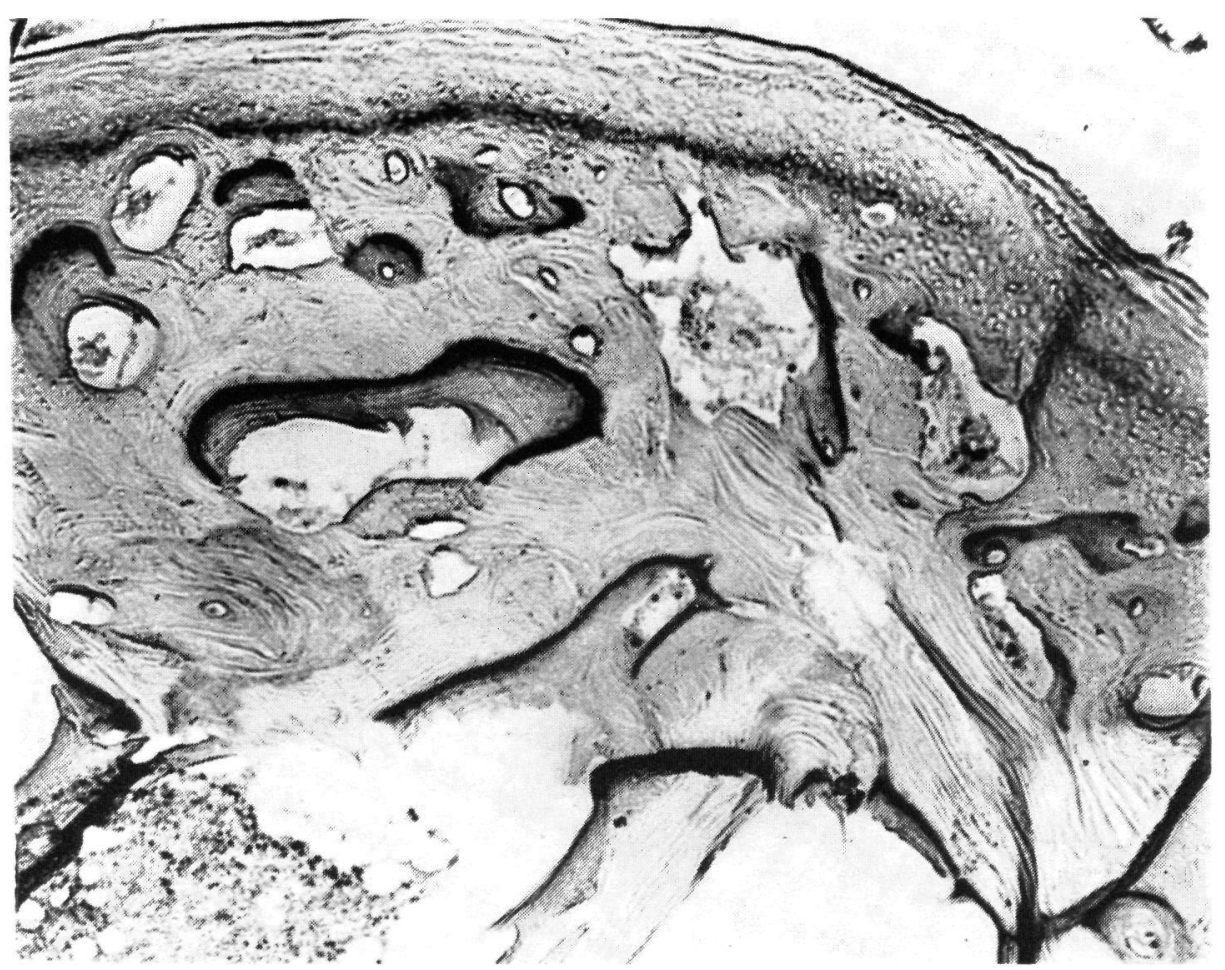

Fig. 8b. From same specimen as Fig. 8a. Proline labeling does not establish any pattern of functional adaptive bone change. (Original magnification $\times 78$.)

to findings in other older monkeys without altered occlusion. The $\mathrm{H}^{3}$ thymidine labelling did not indicate any localized areas of unusual cell proliferation.

Number 5 (19 months experimental interval). Both temporomandibular joints were very similar to monkey 4 (16 $\frac{1}{2}$ month monkey), but with even less indication of rebuild- 


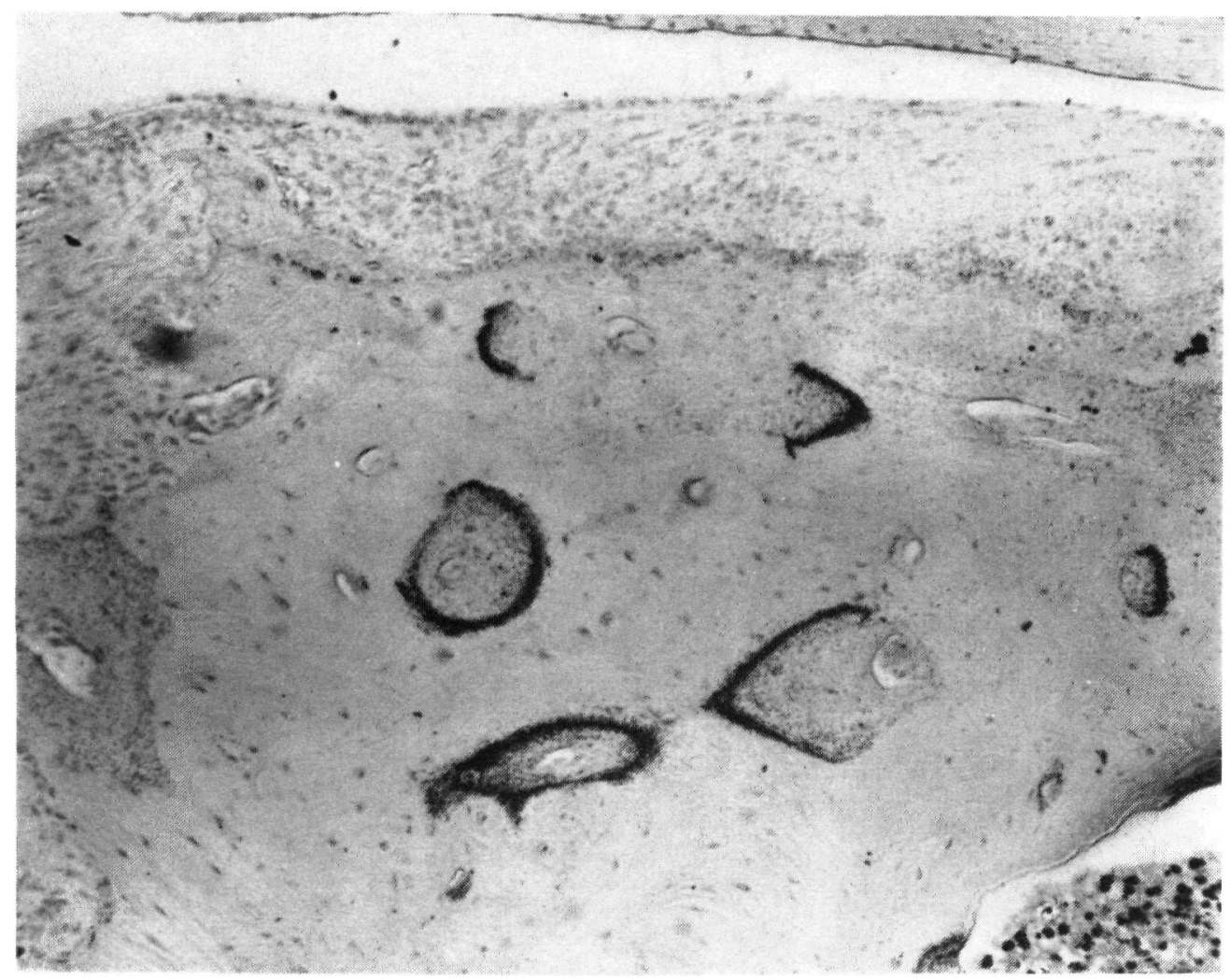

Fig. 9. Section from anterior aspect of the left TMJ in monkey 4. Proline labeling indicates rebuilding of haverian canals, but no directional growth pattern.

ing of the normal appearing right and left temporomandibular joints. Most active formation of bone was seen on the posterio-medial aspect of the left condyle. Degenerative and ageing changes of the joint structures were observed as described for monkey 4.

\section{Periodontal findings}

Monkey $l$ ( $2 \frac{1}{2}$ week experimental animal). Evidence of trauma from occlusion varied from mild to severe. The most severe traumatic manifestations were in the furcation areas. Several teeth showed no evidence of trauma. There was mild chronic incipient periodontitis.

Monkey 2 ( $4 \frac{1}{2}$ month experimental animal). Severe active trauma from occlusion was observed for most of the teeth. In some instances there was direct contact between the roots of the teeth and the alveolar bone in the bi- and trifurcation areas. The maxillary teeth had been moved to the left side (maxillary right teeth in palatal direction, left maxillary teeth in a buccal direction, while mandibular right posterior teeth were moved buccally and the left teeth lingually).

Monkey 3 (6 month experimental animal). The findings were similar to the $4 \frac{1}{2}$ month specimen described above, but the trauma from occlusion was less severe.

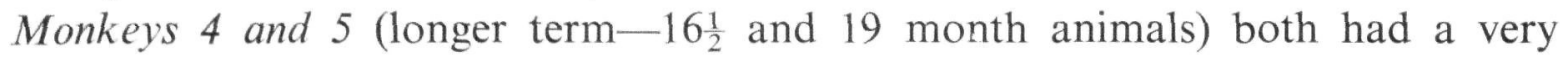
similar periodontal status. The general movement patterns of the teeth as described for the short term animals (1,2 and 3) still could be observed but only few areas showed evidence of active traumatic injury, while areas of previous resorption and repair could be seen both on the roots and at the surfaces of the alveolar bone (Fig. 10). Some of the posterior maxillary teeth on the left side had moved through the buccal bone plate, and the buccal roots were covered only by soft tissues. 


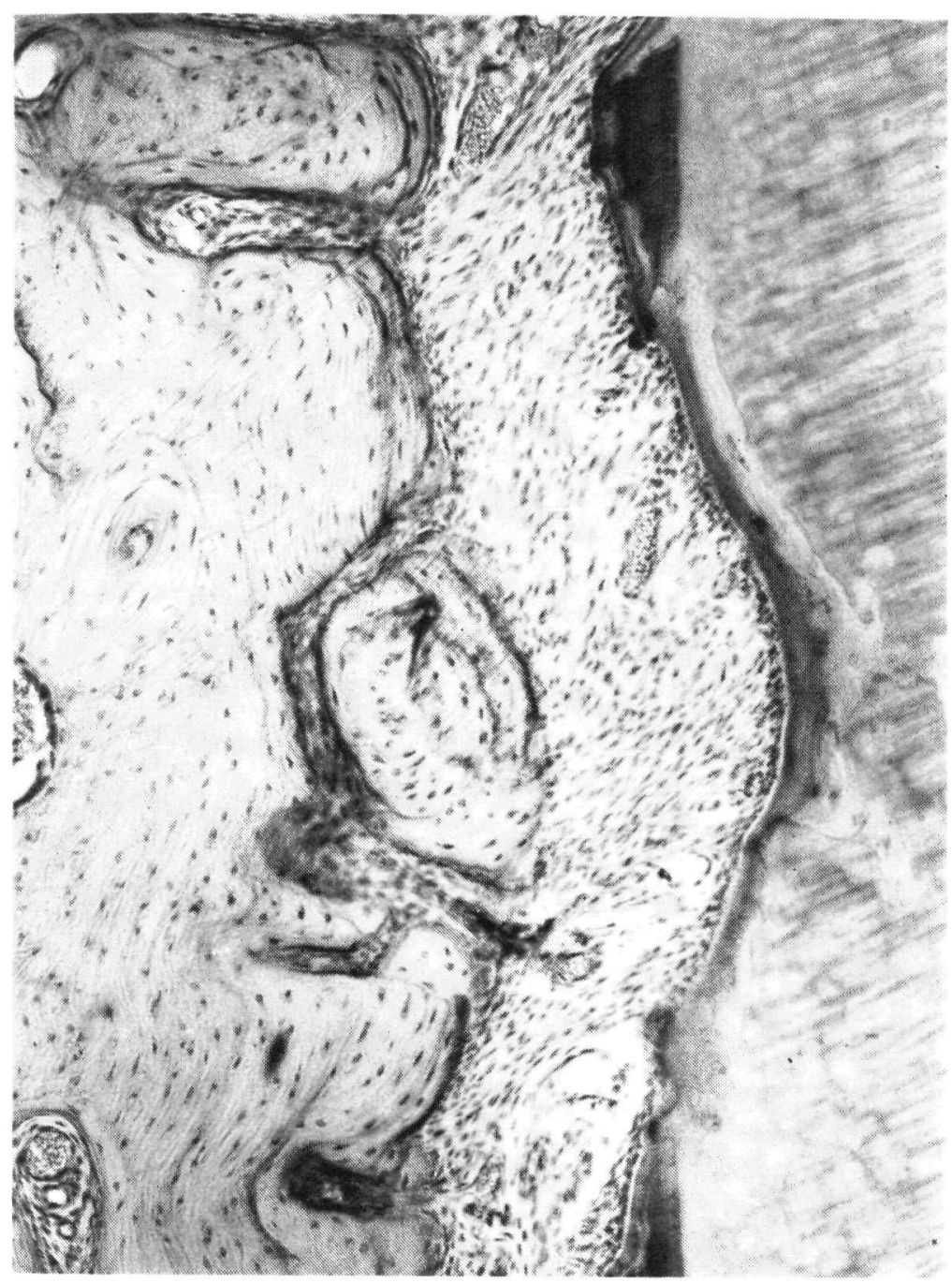

Fig. 10. Periodontal structures from long term monkey 5. Note resorption and repair of cementum and dentine. No evidence of trauma at the time of sacrifice. (Original magnification $\times 150$.)

The layers of bone formed after the administration of $\mathrm{H}^{3}$ proline indicated only slight tooth movements during the 4 months to the sacrifice of the animal. Although the movement patterns in most instances were laterally as described for the short term experiments (1,2 and 3), there also were indications of intrusion of the posterior teeth and elongation of the front teeth.

The $\mathrm{H}^{3}$ thymidine labelling did not reveal any localized trends of cellular activity related to the altered forces on the teeth.

\section{Discussion}

Lateral displacement of the mandible caused a much more severe functional disturbance for the monkeys than the short term transient discomfort reported for anterior and distal displacement (Hiniker \& Ramfjord, 1966; Ramfjord \& Hiniker, 1966; Ramfjord \& Enlow, 1971). The prolonged weight loss and the death of one monkey apparently from lack of intake of food indicated that the occlusal dysfunction must have been very painful. The pain resulting from the experimental lateral displacement confirmed the observations of Carlsson et al., (1967) in humans that a lateral slide from centric relation to centric occlusion may result in an injury to the lateral or medial parts of the joints. These areas are highly innervated (Thilander, 1961) in contrast to the central parts of the articulating structures which apparently are devoid of nerve endings. 
Surprisingly minor evidence of traumatic injury to the tissues could be found in the lateral and medial aspects of the condyles, compared to the severe trauma manifestated in the periodontal structures even with all teeth in each of the jaws splinted together. The articulating joint surfaces evidently had provided a very stress resistant guidance to force applied to the mandible since these surfaces did not show any evidence of injury or adaptive changes. This stability of the articular surfaces confirmed our previous reports (Hiniker \& Ramfjord, 1966; Ramfjord \& Hiniker, 1966; Ramfjord \& Enlow, 1971) and the recent extensive and well-controlled investigation by McNamara (1972) indicating a remarkable stability of the articulating surfaces of the temporomandibular joint in adult monkeys.

The refusal to masticate following the insertion of the appliance indicates that the peripheral tissues and capsular ligaments of the temporomandibular joint may signal considerable pain without remarkable histological evidence of injury to these relatively avascular tissues. The periodontal trauma actually was less severe in this than in our previous studies (Hiniker \& Ramfjord, 1966; Ramfjord \& Hiniker, 1966; Ramfjord \& Enlow, 1971), but in the previous studies the masticatory function of the monkeys was much less impeded. Part of the pain also may have originated at the insertion of the lateral pterygoid muscles since the pterygoid fovea s.towed evidence of bone resorption and repair presumably related to overwork of the muscles.

For interpretation of histological material, it is very important to be aware of the morphological peculiarities and normal variations in shape of the condyles in adult Rhesus monkeys and the impossibility to standardize the plane of sectioning for accurate comparison of findings. Therefore, reports of trauma and functional remodelling of the temporomandibular joint judged from histological sections should be viewed with caution unless vital stains have been used, and even then it is hazardous to compare measurements due to normal morphological variation both on the surfaces and within the trabeculation and haversian canal systems.

In retrospect it appears that the radioactive proline labelling also should have been used for the short term animals. However, the fact that the bony surfaces of the joints did not show any adaptive changes during the last 4 months of the long term experimental intervals, while the teeth splinted in rigid appliances moved during this time, testifies to the stability of the joints. The lack of a functionally directed reorientation during the remodelling of the haversian canal system as revealed by the isotope labelling should emphasize the potential fallacy of interpreting histologic evidence of bone remodelling in the condylar areas as functional adaptation of the temporomandibular joint to changes in occlusal function. Unquestionably there is remodelling of bone in the temporomandibular areas as pointed out by several investigators (Moffett et al., 1964; Blackwood, 1966; Carlsson \& Öberg, 1974) but the assumption by these investigators that this remodelling is evidence of adaptation to altered functional demand has never been proved. On the contrary it has not been possible to change the joints in adult animals by altered functional demands (Hiniker \& Ramfjord, 1966; Ramfjord \& Hiniker, 1966; Ramfjord \& Enlow, 1971; McNamara, 1972; Lieb, 1968; Pietrokovski, 1970; Ramfjord, Walden \& Enlow, 1971). It is also difficult to separate between osteoarthritic changes and functional remodelling (Öberg, Carlsson \& Fajers, 1971; Toller, 1973) and until somebody can verify experimentally the concept of functional remodelling in adults as a physiological phenomenon in response to altered occlusion, such theories cannot be accepted as scientific facts. 


\section{Conclusions}

1. Lateral displacement to a faulty centric occlusion is apt to be more painful than anterior or posterior displacement.

2. The articulating surfaces of temporomandibular joints in adults appear to be remarkably resistant to injury and not readily subject to remodelling following change in functional forces.

3. In a conflict between joint guidance and tooth guidance, the teeth will move, even if splinted, and the neck of the condyles may be remodelled, but the articulating surfaces are stable.

4. There may be severe pain associated with mandibular dysfunction without remarkable histological evidence of injury to the joint structures.

5. Evidence of remodelling of the intrabony haversian canal systems and the trabecular system of the bone in the condyle area does not necessarily signify functionally oriented remodelling of the joint surfaces.

\section{Acknowledgment}

The histological sections and the radio-autographs were prepared by Jean I. Simons at the Veterans Administration Hospital, Ann Arbor, Michigan.

\section{References}

Blackwood, H.J.J. (1966) Cellular remodeling in articular tissue. Journal of Dental Research, 45, 480.

Carlsson, G.E. et al. (1967) Morphological changes in the mandibular joint disc in temporomandibular joint pain dysfunction syndrome. Acta Odontologica Scandinavica, 25, 163.

Carlsson, G.E. \& ÖBerg, T. (1974) Remodeling of the temporomandibular joint. Oral Science Review, 6, 53.

Hiniker, J.J. \& RAMFJORD, S.P. (1966) Anterior displacement of the mandible in adult rhesus monkeys. Journal of Prosthetic Dentistry, 16, 503.

LiEB, G. (1968) Application of the activator in rhesus monkeys. European Orthodontic Society. Transactions, 44, 141.

MCNamara, J.A., JR. (1972) Neuromuscular and skeletal adaptations to altered orofacial function. Center for Human Growth and Development, The University of Michigan, Ann Arbor, Michigan.

Moffett, B., Johnson, L.C., MCCABE, J.B. \& Askew, H.C. (1964) Articular remodeling in the adult human temporomandibular joint. American Journal of Anatomy, 115, 119.

ÖberG, T., Carlsson, G.E. \& Fajers, C.-M. (1971) The temporomandibular joint. A morphologic study on a human autopsy material. Acta Odontologica Scandinavica, 29, 349.

Pietrokovski, J. (1970) Tooth drift and changes in the temporomandibular joint following tooth extraction in the monkeys. Journal of Periodontology, 41, 353.

RAMfJord, S.P. \& HinikeR, J.J. (1966) Distal displacement of the mandible in adult rhesus monkeys. Journal of Prosthetic Dentistry, 16, 491.

RAMFJoRD, S.P. \& ENLOW, R.D. (1971) Anterior displacement of the mandible in adult rhesus monkeys: Long term observations. Journal of Prosthetic Dentistry, 26, 517.

RamfJord, S.P., WALDEN, J.M. \& ENLOW, R.D. (1971) Unilateral function and the temporomandibular joint in rhesus monkeys. Journal of Oral Surgery, Oral Medicine and Oral Pathology, 32, 236.

Thilander, B. (1961) Innervation of the temporomandibular joint capsule in man. Royal School of Dentistry, Stockholm. Transaction, 7, 9.

Toller, P.A. (1973) Osteoarthrosis of the mandibular condyle. British Dental Journal, 134, 223.

Manuscript accepted 28 January 1975 
This document is a scanned copy of a printed document. No warranty is given about the accuracy of the copy. Users should refer to the original published version of the material. 